\title{
Comparison of empirical models with intensively observed data for prediction of salt intrusion in the Sumjin River estuary, Korea
}

\author{
D. C. Shaha and Y.-K. Cho \\ Faculty of Earth System \& Environmental Science, Chonnam National University, Gwangju 500-757, Korea
}

Received: 6 January 2009 - Published in Hydrol. Earth Syst. Sci. Discuss.: 6 March 2009

Revised: 12 June 2009 - Accepted: 22 June 2009 - Published: 26 June 2009

\begin{abstract}
Performance of empirical models has been compared with extensively observed data to determine the most suitable model for prediction of salt intrusion in the Sumjin River estuary, Korea. Intensive measurements of salt intrusion were taken at high and low waters during both spring and neap tide in each season from August 2004 to April 2007. The stratification parameter varied with the distance along the estuary, tidal period and freshwater discharge, indicating that the Sumjin River estuary experiences a transition from partially- or well-mixed during spring tide to stratified during neap tide. The salt intrusion length at high water varied from $13.4 \mathrm{~km}$ in summer 2005 to $25.6 \mathrm{~km}$ in autumn 2006. The salt intrusion mostly depends on the freshwater discharge rather than spring-neap tidal oscillation. Analysis of three years observed salinity data indicates that the scale of the salt intrusion length in the Sumjin River estuary is proportional to the river discharge to the $-1 / 5$ power. Four empirical models have been applied to the Sumjin River estuary to explore the most suitable model for prediction of the salt intrusion length. Comparative results show that the Nguyen and Savenije (2006) model, developed under both partiallyand well-mixed estuaries, performs best of all models studied (relative error of $4.6 \%$ ). The model was also applied under stratified neap tide conditions, with a relative error of 5.2\%, implying applicability of this model under stratified conditions as well.
\end{abstract}

\section{Introduction}

An estuary, which is a semi-enclosed transitional waterbody where freshwater meets saltwater, is known to be one of the most valuable natural, economic and cultural resources. The

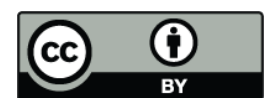

Correspondence to: Y.-K. Cho

(ykcho@chonnam.ac.kr) salinity intrusion in an estuary is maintained by the competition between two opposing longitudinal salt fluxes - an advective flux resulting from freshwater outflow, tending to drive salt out of the estuary; and a gradient salt flux (fluxes from high to low salinity) tending to drive salt landward (Fischer et al., 1979; Geyer and Signell, 1992). Although freshwater discharges, along with tides, largely control the distribution of salinity in an estuary, transport and mixing processes can also be significantly affected by wind if the estuary is wide $(\mathrm{Ji}, 2008)$. However, the flow in a narrow estuary may be predominantly tidal, where the wind has minimum impact on the flow in the long term. Uncles and Stephens (1996) found that the salt intrusion is a strong function of the spring-neap tidal state, but a weaker function of the freshwater inflow in the Tweed Estuary, UK. In many rivers, water is withdrawn for irrigation and drinking purposes, and if contaminated by salt from the sea, is no longer useable (Aerts et al., 2000). The recommended threshold values of salinity for agriculture and drinking purposes are less than 1 and $0.5 \mathrm{ppt}$, respectively.

The Sumjin River estuary is one of the few natural estuaries located on the south coast of Korea. The Sumjin river water supply system consists of two multipurpose and four small water supply dams. Due to seasonal fluctuations in precipitation and runoff (decreasing trend in winter and spring; increasing trend in summer), dams in the Sumjin river play a vital role in supplying water to Domin AC (Agricultural Cooperation) for irrigation of the nation's leading rice fields (Kim, 2000). Increasing upstream seawater intrusion is the major environmental problem in this estuary, which may be caused by upstream dam construction decreasing stream flow, and extraction of sand and gravel, which lowers the stream bottom level (Lee, 2005). Therefore, a model is essential to assess the salt intrusion length as a function of directly measurable parameters, such as geometry, freshwater discharge and tide, to mitigate these problems. There are three main study methods for detecting saltwater

Published by Copernicus Publications on behalf of the European Geosciences Union. 
intrusion: the material analysis method, the empirical correlation method and the use of numerical simulation technology. In the material analysis method, the surveyed hydrological and water resources data, as well as the water flow variation and saltwater intrusion states are analyzed. Based on the material analysis method, Pritchard (1956) and Bowden (1966) explained the distribution of saltwater and the mixing characteristics of saltwater and freshwater. The empirical correlation method refers to searching for an empirical formula, using a large number of historical data relating to the river discharge and salinity in estuaries, and forecasting the effect on saltwater intrusion due to changes in discharge. Numerical simulation based on the advective-diffusive equation of salinity combined with hydrodynamic equations, and predictive equations for salt intrusion can be used to determine the different influences on saltwater intrusion under different boundary conditions.

Water managers require a predictive model for the management of estuarine water resources as functions of geometry, freshwater flow and tide (Savenije, 1993). Two types of predictive models currently exist: those based on laboratory experiments in channels of constant cross-section, and those based on real estuaries. Van der Burgh (1972), Fischer (1974) and Savenije (1993) performed an empirical analysis when predicting salinity intrusion. The models of Van der Burgh (1972) and Savenije (1993) were based on real estuaries, whereas the model of Fischer (1974) was based on laboratory experiments. Savenije (1993) used an exponential function to describe the estuarine geometry, whereas Thatcher and Harleman (1972) used observed cross-sections of the estuary. In 2005, Savenije slightly improved and generalized his 1993 model based on an enlarged database of well-mixed alluvial estuaries. Nguyen and Savenije (2006) further elaborated this method for partially- and well-mixed estuaries, using observation in the Mekong delta branches.

The main purpose of this study is to (i) examine the variation in the salinity intrusion length in response to freshwater input and tide in the Sumjin River estuary, (ii) compare the performance of empirical models, with three years of observation data, to determine the most suitable model for predicting the salt intrusion length, and (iii) examine whether the model developed by Nguyen and Savenije (2006) for partially- and well-mixed estuaries is applicable under stratified neap tide conditions.

The rest of this paper is organized as follows. The data sources are briefly presented in Sect. 2. Empirical models are described in the Sect. 3. Observed and model salt intrusion lengths, and a statistical analysis for the model performance are presented in Sect. 4. A discussion follows in Sect. 5, with the conclusions summarized in Sect. 6 .

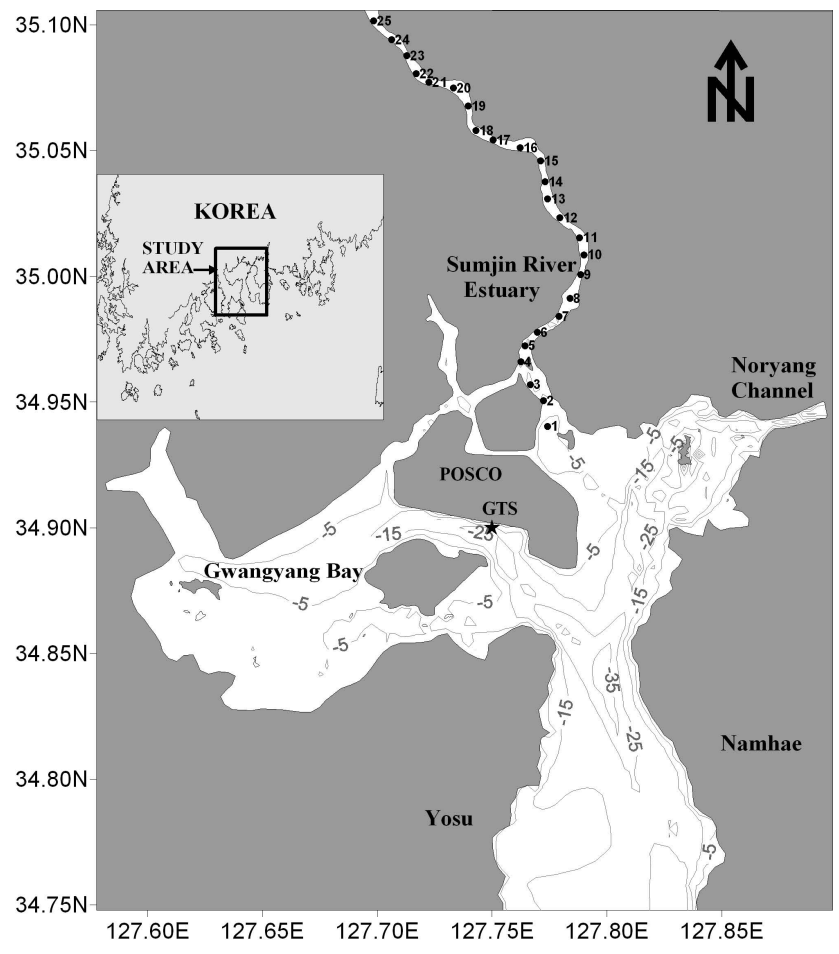

Fig. 1. Map of the study area. The solid circles indicate CTD stations. The star mark denotes the Gwangyang tidal station.

\section{Data sources}

The Sumjin River estuary enters the Gwangyang Bay located on the south coast of Korea (Fig. 1). The length of the Sumjin River estuary is $212 \mathrm{~km}$, with a watershed area of almost $4900 \mathrm{~km}^{2}$, including farmland. The Sumjin River splits into the east and west channels near the POSCO (Pohang Iron and Steel Company) before it enters the Gwangyang Bay. The flow in the east channel is northward during the flood tide and southward during the ebb tide. However, this pattern is reversed in the west channel of the POSCO. Therefore, the east channel is chosen as estuary mouth. The bay is connected in the south to the coastal sea (South Sea) and in the east to Jinjoo Bay through the narrow Noryang Channel (Fig. 1). Topographic information has been collected from the Regional Construction and Management Office of the Construction Department, the Ministry of Construction. The cross-sectional area $\left(\mathrm{m}^{2}\right)$, width $(\mathrm{m})$ and mean depth $(\mathrm{m})$ of the Sumjin River from the mouth (station 1) to a landward location (station 25) are shown in Fig. 2. The convergence lengths of the cross-sectional area (a) and width (b) are 12600 and $87200 \mathrm{~m}$, respectively.

The river discharge data from the Songjung gauge station, located about $10 \mathrm{~km}$ upstream from CTD station 25, were used in this study. The river discharge and tidal range on the date (s) of the field observations from July 2004 to June 2007 are given in Table 1. The climate of Korea is characterized 
Table 1. River discharges and tidal ranges during the three years of field observations.

\begin{tabular}{|c|c|c|c|c|c|c|c|}
\hline \multirow{2}{*}{ Year } & \multirow{2}{*}{ Season } & \multicolumn{3}{|c|}{ Spring tide } & \multicolumn{3}{|c|}{ Neap tide } \\
\hline & & River discharge $\left(\mathrm{m}^{3} \mathrm{~s}^{-1}\right)$ & Tidal range $(\mathrm{m})$ & Salt Intrusion length (km) & River discharge $\left(\mathrm{m}^{3} \mathrm{~s}^{-1}\right)$ & Tidal range $(\mathrm{m})$ & Salt Intrusion length $(\mathrm{km})$ \\
\hline 2004 & Summer & 46 & 3.09 & 17.7 & 26 & 1.22 & 17.9 \\
\hline 2004 & Autumn & 29 & 3.86 & 21.0 & 22 & 1.60 & 18.7 \\
\hline 2005 & Winter & 10 & 3.14 & 23.7 & 16 & 1.04 & 19.1 \\
\hline 2005 & Spring & 18 & 3.51 & 22.9 & 26 & 0.73 & 17.3 \\
\hline 2005 & Summer & 58 & 2.45 & 17.9 & 77 & 1.20 & 13.4 \\
\hline 2005 & Autumn & 16 & 3.92 & 22.8 & 13 & 0.97 & 20.7 \\
\hline 2006 & Winter & 19 & 3.17 & 23.8 & 14 & 1.12 & 18.7 \\
\hline 2006 & Spring & 11 & 3.84 & 24.8 & 30 & 0.52 & 18.0 \\
\hline 2006 & Summer & 50 & 2.93 & 17.9 & 44 & 0.92 & 15.9 \\
\hline 2006 & Autumn & 9 & 3.99 & 25.6 & 15 & 1.87 & 22.7 \\
\hline 2007 & Winter & 12 & 3.85 & 25.5 & 11 & 1.32 & 21.0 \\
\hline 2007 & Spring & 21 & 3.03 & 24.4 & 14 & 0.84 & 20.3 \\
\hline
\end{tabular}

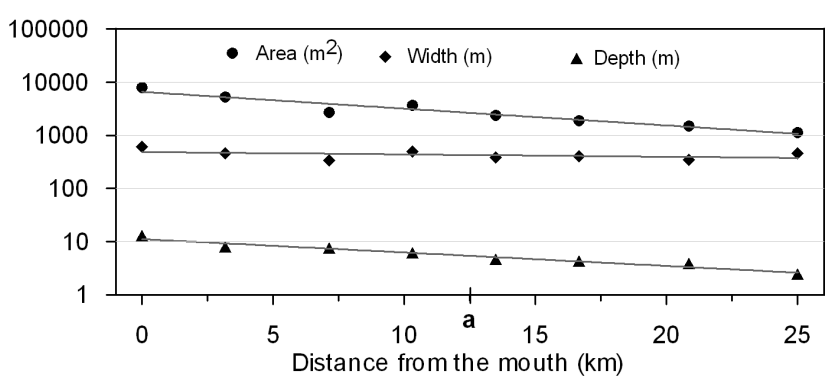

Fig. 2. Cross-section area (circles), width (diamonds) and depth (triangles) of the Sumjin River estuary. $a$ is the cross-sectional convergence length calculated using Eq. (3).

by four distinct seasons: winter (December, January, February); spring (March, April, May); summer (June, July, August); autumn (September, October, November). The summer season, in general, is more prone to high river discharges, while the remaining seasons are susceptible to low river discharges. The maximum monthly median river discharge appeared to be higher $\left(370 \mathrm{~m}^{3} \mathrm{~s}^{-1}\right)$ during July 2006 and lower $\left(11 \mathrm{~m}^{3} \mathrm{~s}^{-1}\right)$ during January 2005 . The tidal information was collected from the Gwangyang Tidal Station (see in Fig. 1) operated by the National Oceanographic Research Institute, Korea. The tidal cycle is semi-diurnal, with mean spring and neap ranges of 3.40 and $1.10 \mathrm{~m}$, respectively. Based on the tidal range criterion of Davies (1964), this estuary can be characterized as mesotidal and microtidal during spring and neap tide, respectively. The $\mathrm{M}_{2}$ tide $(1.05 \mathrm{~m})$ is the primary tidal constituent at the river mouth.

The longitudinal transects for salinity and temperature were taken at high and low waters during both spring and neap tide for each season, from August 2004 to April 2007, using a CTD profiler (IDRONAUT Company). Four samples (spring high water, spring low water, neap high water, neap low water) were taken in each season. GPS was used to obtain the exact locations. The nominal distance between CTD stations was $1 \mathrm{~km}$. Each cruise started from the mouth about one hour before high or low water and took approximately one hour to arrive at the last station when high or low water slack occurred (Fig. 1). The number of observation stations along the estuary for each cruise varied between 13 and 25 , depending on the change in the water depth with the tide. It was not possible to proceed upstream at low water due to the shallower depth. As a result, it was not possible to survey all upstream stations at low water. To examine the maximum salt intrusion length, only the high water slack data surveyed from August 2004 to April 2007 were used in this study.

\section{Methodology}

Steady state salt intrusion models can be divided into three types, based on their derivation: low water slack (LWS), tidal average (TA) and high water slack (HWS) models (Savenije, 2005). A HWS model is verified with salinity measurements carried out at HWS and a LWS model with salinity measurements carried out at LWS. For a TA model, the salinity measurements are carried out for a full tidal cycle, after which they are averaged.

Van der Burgh (1972) provided a tidal average model using limited field observations in real estuaries, including the Rotterdam Waterway, the Schelde and the Haringvliet. It is defined as:

$L^{\mathrm{TA}}=24 \pi \frac{h_{0}}{K} F^{-0.5} N^{-0.5}$

where $L^{\mathrm{TA}}$ is the tidal averaged intrusion length, $h_{0}$ is the tidal average depth, $F$ is the Froude number $(F=$ $v_{0} / \sqrt{(g h)}$ ), and $N$ is the Canter-Cremers estuary number, which is defined as the ratio of the freshwater entering the estuary during a tidal cycle $\left(Q_{f} T\right)$ to the flood volume of saltwater entering the estuary over a tidal cycle $\left(P_{t}=A_{0} E_{0}\right)$. Savenije (2005) showed that the flood volume can be very well approximated by the product of $A_{0}$ and the tidal excursion $E_{0}\left(=v_{0} T / \pi\right)$ at the estuary mouth. $K$ is the Van der 
Burgh coefficient, for which Savenije (2005) developed an empirical predictive equation:

$$
\begin{aligned}
& K=0.2 \times 10^{-3}\left(\frac{E}{H}\right)^{0.65}\left(\frac{E}{C^{2}}\right)^{0.39}(1-\delta b)^{-2.0} \\
& \left(\frac{b}{a}\right)^{0.58}\left(\frac{E a}{A_{0}}\right)^{0.14}
\end{aligned}
$$

where $K$ is Van der Burgh's coefficient, which is a hydraulic characteristic of estuaries, which has a value between 0 and 1. $E$ is the tidal excursion, defined as the difference between the intrusion length at HWS and LWS, $H$ is the tidal range, $C$ is the Chezy coefficient, $\delta$ is the damping rate of the tidal range $(\delta=(1 / H)(\partial H / \partial x))$ and $A_{0}$ is the cross-sectional area at the estuary mouth. The area convergence length $(a)$ and width convergence length $(b)$ are defined by exponential functions (Savenije, 2005):

$$
\begin{aligned}
& A=A_{0} \exp \left(-\frac{x}{a}\right) \\
& B=B_{0} \exp \left(-\frac{x}{b}\right)
\end{aligned}
$$

where $A$ and $B$ are the cross-sectional area and width at a distance $x(\mathrm{~km})$ from the estuary mouth, respectively. $A_{0}$ and $B_{0}$ are the cross-sectional area and width at the estuary mouth $(x=0)$, respectively.

Fischer (1974) derived the following formula for low water slack conditions:

$$
L^{\mathrm{LWS}}=17.7 \frac{h_{0}}{f^{0.625}} F_{d}^{-0.75} N^{-0.25}
$$

where $L^{\mathrm{LWS}}$ is the intrusion length at LWS (the minimum intrusion length occurring during a tidal period), $f$ is the DarcyWeisbach friction factor $\left(f=8 g / C^{2}\right)$ and $F_{d}$ is the densimetric Froude number $\left(F_{d}=\left(\rho v_{0}^{2} / \Delta \rho g h_{0}\right)\right)$. The major differences between Van der Burgh (1972) and Fischer (1974) models are in the use of the dimensionless numbers, namely $F_{d}, F, K$ and $f$. The exponent of $N$ is different between the two models, which is negative as the salt intrusion length diminishes with increased freshwater discharge. Likewise, the salt intrusion length decreases linearly with the tidal velocity amplitude.

Savenije $(1993,2005)$ developed a method for HWS that predicts the salinity along the estuary depending on the shape of the estuary, the tidal influence and the river discharge. The salt intrusion length, $L$, is defined by (Savenije, 2005):

$L^{\mathrm{HWS}}=a \ln \left(-\frac{D_{0}^{\mathrm{HWS}} A_{0}}{K a Q_{f}}+1\right)$

where $L^{\mathrm{HWS}}$ is the intrusion length at HWS (the maximum intrusion length during a tidal period), $D_{0}^{\mathrm{HWS}}$ is the dispersion coefficient at the estuary mouth at HWS. $K, a$ and $A_{0}$ are (constant) hydraulic characteristics of the estuary and therefore are the same under any condition during the year, whereas $D_{0}^{\mathrm{HWS}}$ is time dependent, depending on both the river discharge and tidal range. The model has been applied to 17 different estuaries all over the world, particularly for HWS situations. $D_{0}^{\mathrm{HWS}}$ was initially generalized and improved by Savenije (2005), and later by Nguyen and Savenije (2006), for partially- and well-mixed estuaries. The dispersion coefficient, $D_{0}^{\mathrm{HWS}}$, is expressed as follows:

$D_{0}^{\mathrm{HWS}}=1400 \frac{\bar{h}}{b} \sqrt{N_{R}}\left(v_{0} E_{0}\right)$

where $\bar{h}$ is the average depth over the salt intrusion length, $v_{0}$ is the tidal velocity amplitude at the estuary mouth, $E_{0}$ is the tidal excursion at the estuary mouth and $N_{R}$ is the Estuarine Richardson number. Equation (7) was slightly modified by Nguyen and Savenije (2006) by replacing the area convergence length (a) with the width convergence length (b) and using the average depth over the salt intrusion length instead of the depth at the estuary mouth for partially- and wellmixed estuaries. The salt intrusion lengths at HWS are well computed by the predictive model using Eqs. (6) and (7). The Estuarine Richardson number (the ratio of the CanterCremers number $N$ to the densimetric Froude number $F_{d}$ ) is the dimensionless number that determines the balance between kinetic energy provided by the tide and potential energy provided by the river discharge through buoyancy of freshwater responsible for the mixing:

$N_{R}=\frac{N}{F_{d}}=\frac{\Delta \rho}{\rho} \frac{g \bar{h} Q_{f} T}{A_{0} E_{0} v_{0}^{2}}$

The models of Van der Burgh (1972) and Savenije (2005) are based on real estuaries, whereas that of Fischer (1974) is based on laboratory tests. The Darcy-Weisbach's coefficient, solely a function of flow roughness, is considered for the Fischer (1974) model. The Van der Burgh coefficient $(K)$ is used in the models of Van der Burgh (1972) and Savenije (2005), which is a function of both the average tidal and freshwater flow characteristics. Savenije (1993) used an exponential model of the estuarine geometry Eqs. (3) and (4) to predict the salt intrusion length. In 2005, Savenije generalized and improved his 1993 model for application to well-mixed alluvial estuaries, with further modifications by Nguyen and Savenije (2006) for partially- and well-mixed estuaries. A time dependent (depending on both the river discharge and tidal range) dispersion coefficient $\left(D_{0}^{\mathrm{HWS}}\right)$ near the estuary mouth is used in Savenije (2005) and Nguyen and Savenije (2006) models. All models described above were applied to the Sumjin River estuary to predict the salt intrusion length assuming a steady state.

In this study, the salt intrusion length at high water during both spring and neap tide has been defined as the length from the river mouth (station 1) along the river channel to the point 
where the bottom salinity was 1 psu. To examine the maximum salt intrusion length, the bottom salinity at high water has been used instead of the depth-averaged salinity. The variation in the salt intrusion was subsequently examined in response to freshwater input and tide. On 26 October 2005, during neap tide, and on 6 November 2006, during spring tide, a salinity of 1 psu did not appear at the last CTD station. Therefore, the data was extrapolated to obtain a salinity of 1 psu. The mean freshwater discharge on the date of the field observation was used to predict the salt intrusion length. Van der Burgh's coefficient, $K$, was calculated from the field data using Eq. (2). The value of this coefficient was 0.76 . The Darcy-Weisbach friction factor was 0.024 . The salinity intrusion lengths were calculated using $h=6.1 \mathrm{~m}, A_{0}=7913 \mathrm{~m}^{2}$, $T=44400 \mathrm{~s}, v_{0}=0.64 \mathrm{~m} \mathrm{~s}^{-1}$ (spring) and $0.34 \mathrm{~m} \mathrm{~s}^{-1}$ (neap). In a narrow estuary, the wind has minimum impact on the flow (Ji, 2008). Therefore, the wind effects were not considered in this study due to narrowing of the Sumjin River estuary.

As the observed intrusion length was determined under a high water slack situation in this study, the tidal excursion, $E$, was added to the LWS model of Fischer (1974) and half the tidal excursion $(E / 2)$ added to the TA model of Van der Burgh (1972) to obtain the high water slack intrusion length. The tidal excursion, the distance between the low and high water locations of a vertically-mixed parcel of water (Uncles and Stephens, 1996), was measured during spring tide in relation to the location of salinity $=27 \mathrm{psu}$. Tidal excursions ranged between 3.0 and $9.4 \mathrm{~km}$ during spring tide (Table 2). The calculated tidal excursion $\left(E=v_{0} T / \pi ; 9 \mathrm{~km}\right)$ for the maximum tidal amplitude is consistent with the observed maximum tidal excursion $(9.4 \mathrm{~km})$.

Statistical analyses have been performed as quantitative measures of how good the model results fitted the data to evaluate model performance. Although numerous methods exist for analyzing and summarizing model performance, the mean absolute error (MAE), root-mean-square (RMS) error and relative error (RE) were used to compare model-data for model calibration and verification in this study. The coefficient of determination, $R^{2}$, has been used in the context of examining the external forcing; either freshwater buoyancy input or tide is the predominant control on salt intrusion in this estuarine system.

\section{Results}

\subsection{Salt intrusion}

To determine the maximum salt intrusion length, the horizontal bottom salinity distributions taken at high water during spring and neap tide for each season in 2004, 2005, 2006 and 2007 are plotted in Figs. 3, 4, 5 and 6, respectively. How the variable river discharges and tide affect the salt intrusion during both spring and neap tide was then assessed. High
Table 2. Estimated tidal excursions during field campaigns.

\begin{tabular}{rcc}
\hline Date & Tidal ranges $(\mathrm{m})$ & Tidal excursions $(\mathrm{km})$ \\
\hline $29 / 1 / 2005$ & 2.85 & 3.4 \\
$8 / 4 / 2005$ & 3.87 & 9.4 \\
$21 / 7 / 2005$ & 2.98 & 3.0 \\
$19 / 10 / 2005$ & 3.59 & 6.8 \\
$16 / 1 / 2006$ & 2.83 & 3.1 \\
$30 / 3 / 2006$ & 3.56 & 7.0 \\
$6 / 11 / 2006$ & 3.60 & 8.0 \\
\hline
\end{tabular}

river discharges occurred during the summer of all years; 2004-2007, with tidal ranges of 2.45-3.10 m during spring tide. The other seasons were susceptible to lower river discharges, with tidal ranges of $3.0-4.0 \mathrm{~m}$. The maximum intrusion length, $25.6 \mathrm{~km}$, occurred for a low river discharge during spring tide on 6 November 2006, while the minimum, $13.4 \mathrm{~km}$, occurred at high river discharge during neap tide on 21 July 2005.

In 2006, the salt intrusion length during spring tide increased by $4 \mathrm{~km}$ during spring and $3 \mathrm{~km}$ during autumn compared to the same period in 2005, which is due to the river discharge and tide (Table 1). In spring of 2006, the intrusion length increased due to a $9 \%$ greater tidal range and $39 \%$ lower river discharge. Similarly, in autumn of 2006, the river discharge was about $50 \%$ less than that in 2005 , whereas the tidal range remained approximately the same. This indicates that the autumn intrusion length was solely affected by the freshwater flow. During summer, the intrusion length was approximately the same as for the spring tide when no significant variations in the river runoff and tide appeared. Conversely, the salt intrusion length during neap tide increased by about $2 \mathrm{~km}$ in both summer and autumn in $2006 \mathrm{com}-$ pared to the same period in 2005 . The freshwater discharge was $42 \%$ less in summer 2006, whereas the tidal range was $19 \%$ less during the same period. Therefore, both the freshwater discharge and the tide are likely causes of the summer increase of salt intrusion. Conversely, the tidal range during neap tide in autumn 2006 doubled, but the freshwater discharge remained almost the same (Table 1). This indicates that the tide is the reason for the autumn increase in the salt intrusion during neap tide in 2006.

Estuaries can be classified by their stratification and mixing patterns. Hansen and Rattray (1966) developed a stratification parameter $(\delta S /\langle S\rangle)$, defined as the ratio of the salinity difference between surface and bottom $(\delta S)$ divided by the depth averaged salinity $\langle S\rangle$, to characterize estuaries. Prandle (1985) showed that $(\delta S /\langle S\rangle)=4 S_{t}^{-0.55}$, where $S_{t}$ is the stratification number $\left(S_{t}=\left(0.85 k v_{0}^{3} L\right) /(\Delta \rho / \rho) g h^{2} u_{m}\right), k$ is the friction coefficient (0.0025), $L$ is the salt intrusion length, $v_{0}^{3}$ is the amplitude of the tidal currents, $h$ is the water depth and $u_{m}$ is the depths mean current. This means that $\delta S /\langle S\rangle<0.15$ 


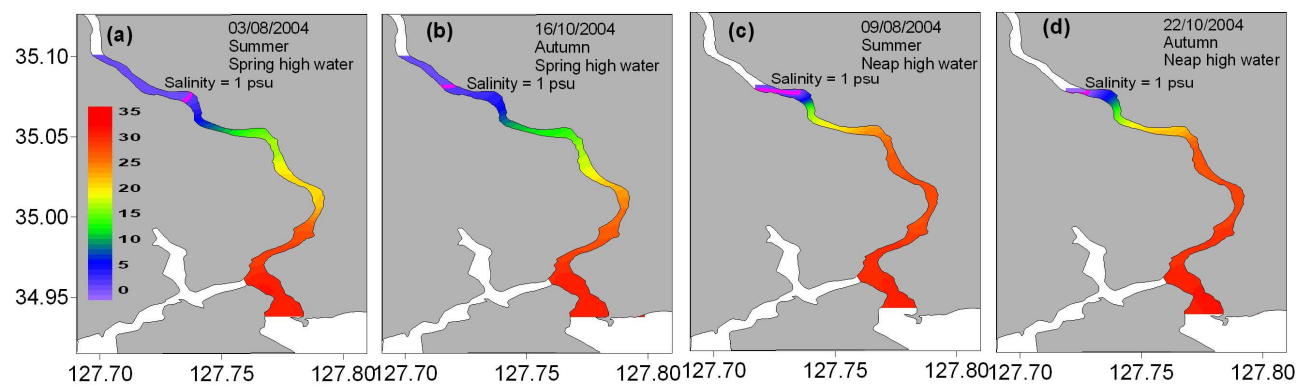

Fig. 3. Horizontal bottom salinity distribution at high water during spring (a, b) and neap (c, d) tides for summer and autumn 2004. The pink band indicates the limit of salinity $=1 \mathrm{psu}$.
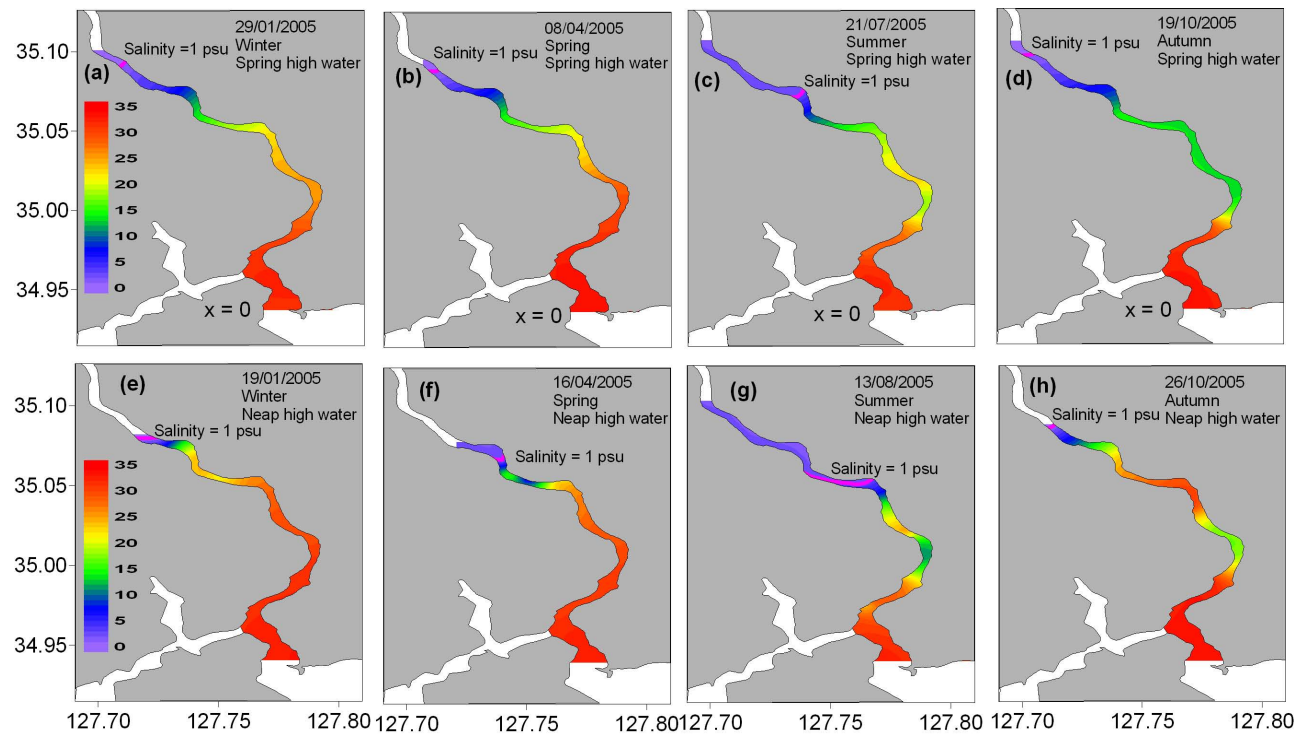

Fig. 4. Horizontal bottom salinity distribution at high water during spring (a, b, c, d) and neap (e, $\mathbf{f}, \mathbf{g}, \mathbf{h})$ tides for each season during 2005. The pink band indicates the limit of salinity $=1 \mathrm{psu}$.

is well mixed and $\delta S /\langle S\rangle>0.32$ is stratified. In this study, the stratification parameter was calculated for all stations using data surveyed during both spring and neap tide for each season in the Sumjin River estuary (Fig. 7). Maximum values of the stratification parameter, $\delta S /<S>$, occurred during neap tide, with minimum values during spring tide. During spring tide, the lowest values $(<0.15)$ of the estimated $\delta S /<S>$ generally occurred down the estuary, up to about $5 \mathrm{~km}$ from the mouth, indicating the occurrence of well-mixed conditions, while at the same time, higher values, between 0.15 and 0.32 , occurred in the remaining upper portion, suggesting partially mixed conditions. Highly stratified conditions $(>0.32)$ occurred throughout the estuary during neap tide, with maximum values occurring in the halocline. The stratification parameter varies depending on the location along the estuary, tidal period and freshwater discharge, indicating that the Sumjin River estuary experiences a transition from partially- or well-mixed during spring tide to stratified during neap tide.

\subsection{Model intrusion length}

The Van der Burgh (1972), Fischer (1974), Savenije (2005) and Nguyen and Savenije (2006) models have been applied to the Sumjin River estuary for predicting the salt intrusion length. The models of Van der Burgh (1972), Savenije (2005) and Nguyen and Savenije (2006) are based on real estuaries, whereas that of Fischer (1974) is based on laboratory tests. The quantities needed to predict the salt intrusion length using these empirical models are freshwater inputs to the estuary at various times during the year, tidal information and the bathymetry along the estuary. The salinity intrusion lengths were calculated using $K=0.76, f=0.024$, $h=6.1 \mathrm{~m}, A_{0}=7913 \mathrm{~m}^{2}, T=44400 \mathrm{~s} v_{0}=0.64 \mathrm{~m} \mathrm{~s}^{-1}$ (spring) and $0.34 \mathrm{~m} \mathrm{~s}^{-1}$ (neap). The river discharge on the date of the field observations was used in this study. The wind effects were not considered in this study due to the narrowing of this estuary. 

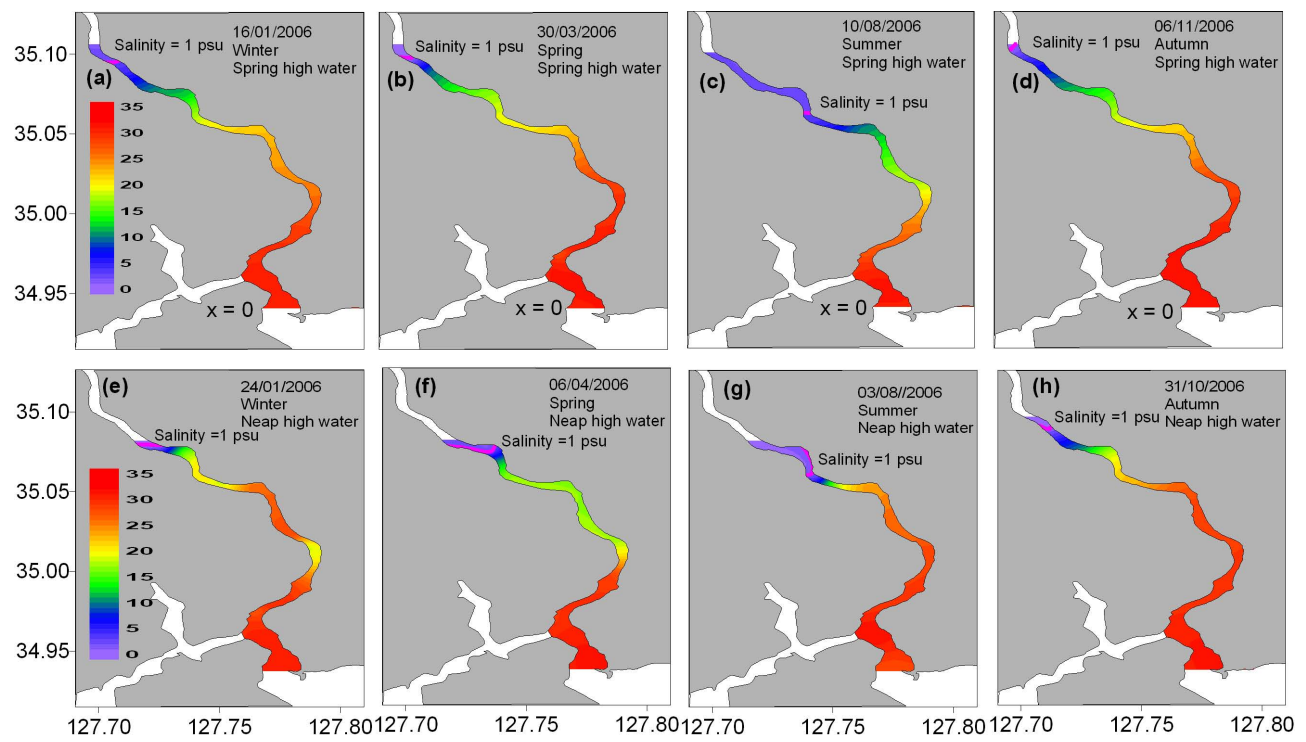

Fig. 5. Horizontal bottom salinity distribution at high water during spring $(\mathbf{a}, \mathbf{b}, \mathbf{c}, \mathbf{d})$ and neap $(\mathbf{e}, \mathbf{f}, \mathbf{g}, \mathbf{h})$ tides for each season during 2006. The pink band indicates the limit of salinity $=1 \mathrm{psu}$.
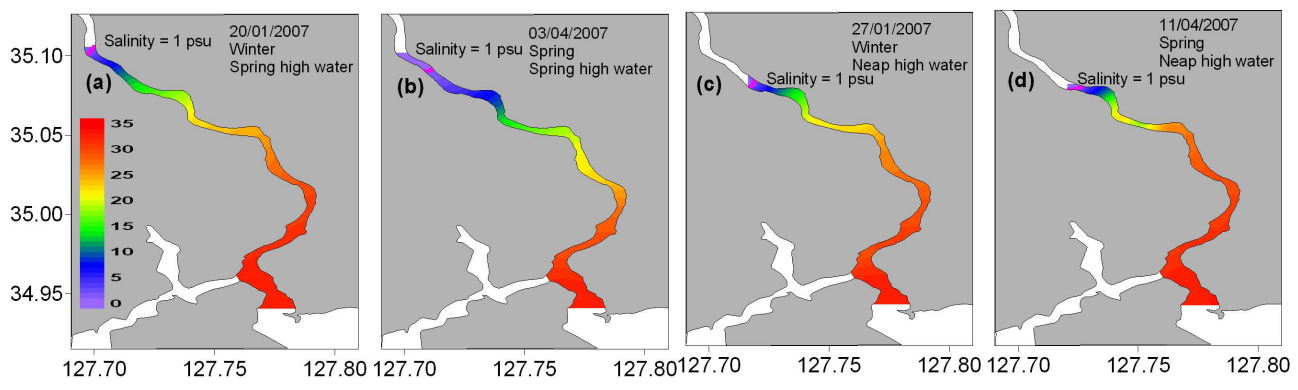

Fig. 6. Horizontal bottom salinity distribution at high water during spring (a, b) and neap (c, d) tides for winter and spring 2007. The pink band indicates the limit of salinity $=1 \mathrm{psu}$.

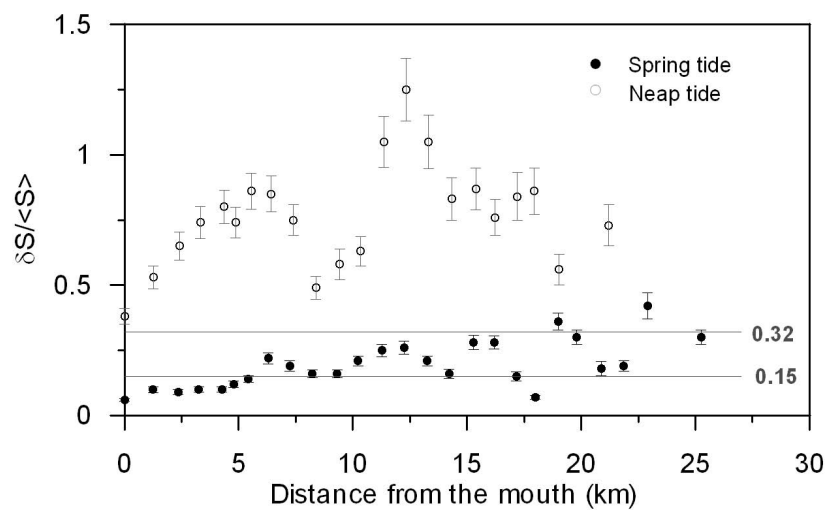

Fig. 7. Stratification parameter for all longitudinal depth surveys of the Sumjin River estuary taken during both spring and neap tide in each season. A value above 0.32 indicates a stratified condition and below 0.15 a well mixed condition.
The most important output of these models is the salt intrusion length (Savenije, 1993). Comparisons between the salt intrusion length of the different predictive formulae and field data are shown in Fig. 8. The Van der Burgh model (1972) predicted the salt intrusion length in low river discharge reasonably well, but overestimated the intrusion length with increasing river discharge during both spring and neap tide (Fig. 8a). The Fischer model (1974) overestimated and underestimated the salt intrusion length during neap and spring tide, respectively (Fig. 8b). The Savenije model (2005) overestimated the salt intrusion length (Fig. 8c), where the area convergence length (a) was used for calculating the dispersion coefficient (Eq. 7). Conversely, the Nguyen and Savenije (2006) model predicted the salt intrusion length quite adequately (Fig. 8d) compared to the Van der Burgh (1972), Fischer (1974) and Savenije (2005) models. The main reasons why the Savenije model (and the same applies to the Nguyen and Savenije model) performs better are: (i) Foremost, it is important to stress that 
Table 3. A summary of the statistics of salinity intrusion lengths in the Sumjin River estuary from 2004 to 2007.

\begin{tabular}{lcccccc}
\hline Models & \multicolumn{2}{c}{ MAE $(\mathrm{km})$} & \multicolumn{2}{c}{ RMS Error $(\mathrm{km})$} & \multicolumn{2}{c}{ Relative Error (\%) } \\
\hline & Spring & Neap & Spring & Neap & Spring & Neap \\
Van der Burgh (1972) & 3.99 & 4.6 & 5.81 & 6.01 & 17.86 & 24.70 \\
Fischer (1974) & 3.50 & 6.18 & 3.96 & 6.37 & 15.68 & 33.14 \\
Savenije (2005) & 22.40 & 21.90 & 22.45 & 21.95 & 100 & 117 \\
Nguyen and Savenije (2006) & 0.90 & 0.96 & 1.16 & 1.11 & 4.04 & 5.20 \\
\hline
\end{tabular}
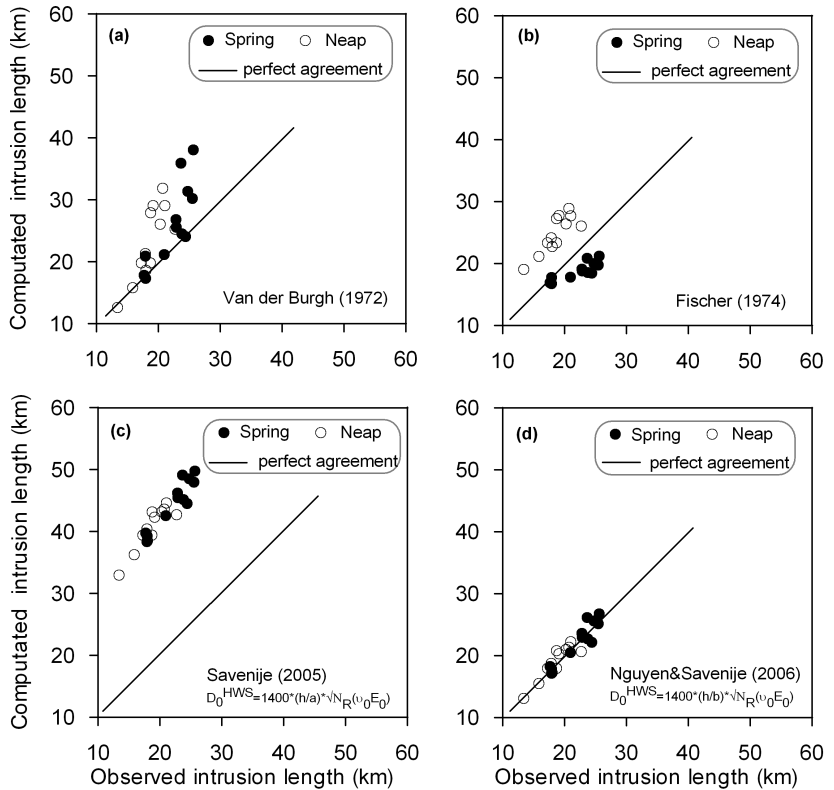

Fig. 8. Comparison of the results of various empirical models: (a) Van der Burgh (1972), (b) Fischer (1974), (c) Savenije (2005) and (d) Nguyen and Savenije (2006), for the salt intrusion length measured at high water during spring and neap tides.

the Savenije model uses the correct functional relationship: $L=a \ln (1+x / a)($ Eq. 6$)$, where others merely use a power function as a regression equation. The exponential shape together with the Van der Burgh model yields this equation. This equation is important, because in prismatic estuaries (when a goes to infinity) $\ln (1+x / a)$ approaches $x / a$, after which follows that $L=x$. This is the equation used by all other researchers where they related $x$ to dimensionless numbers. (ii) The Savenije model uses the convergence length and the tidal excursion in the regression. These are two important length scales: one for the topography and one for the dominant mixing length. (iii) The Savenije model uses the Estuarine Richardson number (the ratio of the CanterCremers number $N$ to the densimetric Froude number $F_{d}$ ), which is the dimensionless number that determines the balance between tidal energy and potential energy responsible for the mixing, and (iv) The Savenije model uses the Van der Burgh coefficient $K$. Parsa et al. (2007) obtained better results with the Van der Burgh model (1972) compared to Savenije (1993) model using the annual average discharge. The variation in the cross-sectional areas of Bahmanshir can not be approximated by an exponential function and; as a result, the Van der Burgh model (1972) provided better result.

Statistical analysis has been used for quantitative comparison of the models studied. The Van der Burgh (1972) and Fischer (1974) models yield smaller relative errors during spring compared to neap tide (Table 3). The Nguyen and Savenije (2006) model, developed under both partially- and well-mixed estuaries, yields the least relative error (4.6\%) of all models studied for both spring and neap tide. The Sumjin River estuary shows highly stratified conditions during neap tide and partially- to well-mixed characteristics during spring tide. The Nguyen and Savenije (2006) model was first applied under stratified neap tide conditions. Of all models studied, this model shows the least relative error of 4.0 and $5.2 \%$ during spring and neap tide, respectively. This indicates that the Nguyen and Savenije (2006) model can also predict the salt intrusion length under stratified neap tide conditions.

\subsection{Dominant controls on salt intrusion length}

There are dams upstream, which play a vital role in supplying water for irrigation. It is important to examine the external forces, either freshwater buoyancy input or tide, that predominantly controls salt intrusion in this estuarine system. Under steady state or tidally averaged (spring-neap tidal cycle) conditions, the salt intrusion length scale, $L$, in a first order approach may be described as a power-law of the river discharge in prismatic estuaries (Monismith et al., 2002):

$L \approx Q^{\alpha}$

where $\alpha$ is the power dependence coefficient. Previous research shown that the power dependence coefficient varies widely under different estuarine conditions. Oey (1984) showed $\alpha \sim-1 / 5$ based on observed data in the Hudson River estuary for the highest flows. Monismith et al. (2002) obtained $\alpha \sim-1 / 7$ for 21 years of observed salinity data in the San Francisco Bay, and pointed out that the weaker dependence of salinity intrusion on flow was due to both the 

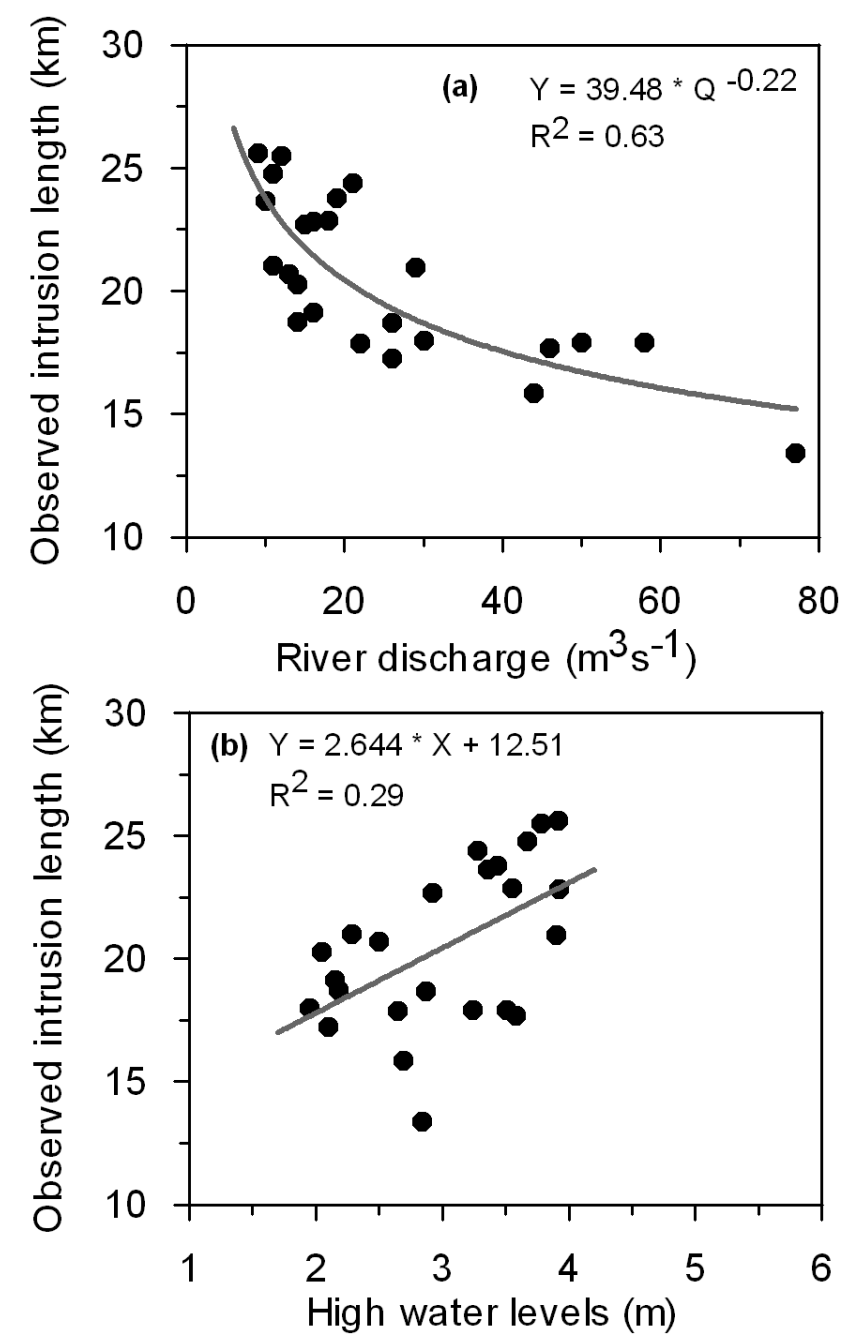

Fig. 9. The power correlation between the salt intrusion lengths measured at high water during spring-neap tides and river discharges (a); observed salt intrusion lengths and high water levels (b).

geometry of San Francisco Bay and the effects of stratification on vertical mixing. The scale of the salt intrusion length for the Sumjin River estuary was found to be proportional to the river discharge to the $-1 / 5$ power based on three years of observed salinity data (Fig. 9a). It has previously been demonstrated (Savenije, 2005) that because of the assumption used of a constant cross-sectional area, different estuaries have different exponents. In addition, a linear relationship has been found between high water levels and the intrusion length (Fig. 9b), to see whether the tide or river discharge is the dominant factor controlling the salt intrusion in this estuarine system. Regression fitting indicated that the salt intrusion greatly depends on the river discharge, but to a lesser extent on the spring-neap tidal oscillation.

\section{Discussion}

In general, tide-driven mixing is dominant downstream, but gravitational mixing upstream of the estuary (Savenije, 2005). Van der Burgh's coefficient, $K$, gives a balance between both mechanisms (Savenije, 2006). Tide-driven mixing becomes dominant near the toe of a salt intrusion when $K$ is small. By contrast, if $K$ approaches unity, then gravitational mixing becomes dominant. In our study, the value of $K$ for the Sumjin River estuary is 0.76 , indicating that gravitational mixing is important near the toe of the salt intrusion. In addition, the flushing rate can be used as an index for tidal and gravitational mixing (Officer and Kester, 1991). The flushing rate $(F)$ is the rate at which the freshwater exchanges with the sea (Officer and Kester 1991). The flushing rate is defined as:

$F_{i}=\frac{V_{i}}{T_{i}}=\frac{Q_{f}}{f_{i}}$

where $V_{i}$ is the volume of the estuary segment and $T_{i}=f_{i} V_{i} / Q_{f}$ is the flushing time of each segment, as defined by Officer (1976) and Dyer (1997). Where $Q_{f}$ is the freshwater discharge and $f_{i}=\left(S_{s w}-S_{i}\right) / S_{s w}$ is the freshwater fraction over any segment, as defined by Officer (1976) and Dyer (1997). $S_{s w}$ is the salinity at the estuary mouth and $S_{i}$ is the mean salinity in a given segment of the estuary.

The quantity, $F$, which has the dimension of $\mathrm{m}^{3} \mathrm{~s}^{-1}$, represents the combined effects of the tidal exchange and the gravitational exchange flux. The tidal exchange flux should be independent of the river discharge, but the gravitational circulation flux is dependent on the river discharge. If there are no tidal exchanges, a plot of $F$ against $Q_{f}$ will give a line, with an intercept of zero. If both tidal exchange and gravitational circulation flux are active, there should be an intercept value, $F_{\text {int }}$, of a plot of $F$ against $Q_{f}$, which represents the tidal exchange, and the amounts in excess of the intercept represent the gravitational circulation flux.

Sheldon and Alber $(2002,2006)$ also suggested that the freshwater fraction method can easily be applied to multiple segments, as the flushing time is the sum (Dyer, 1997) of the segment flushing times. Therefore, this technique has been applied to the upper Sumjin River estuary, near the toe of the salinity curve, by dividing it into two segments. Segment A contains stations 21, 22, 23, 24, 25, and segment B stations 17, 18, 19 and 20. An analysis of three years of observed salinity data indicates that the gravitational flux is dominated in segment A (Fig. 10a), whereas in segment B it is a combination of the gravitational circulation and tidal flux (Fig. 10b). However, the small intercept, $F_{\text {int }}$, for segment B implies strong gravitational circulation and a weak tidal flux. Therefore, the zone near the toe of the salt intrusion curve at maximum salt intrusion length is dependent on the gravitational flux.

Although the Nguyen and Savenije (2006) model was not considered applicable to stratified conditions, it appears to 

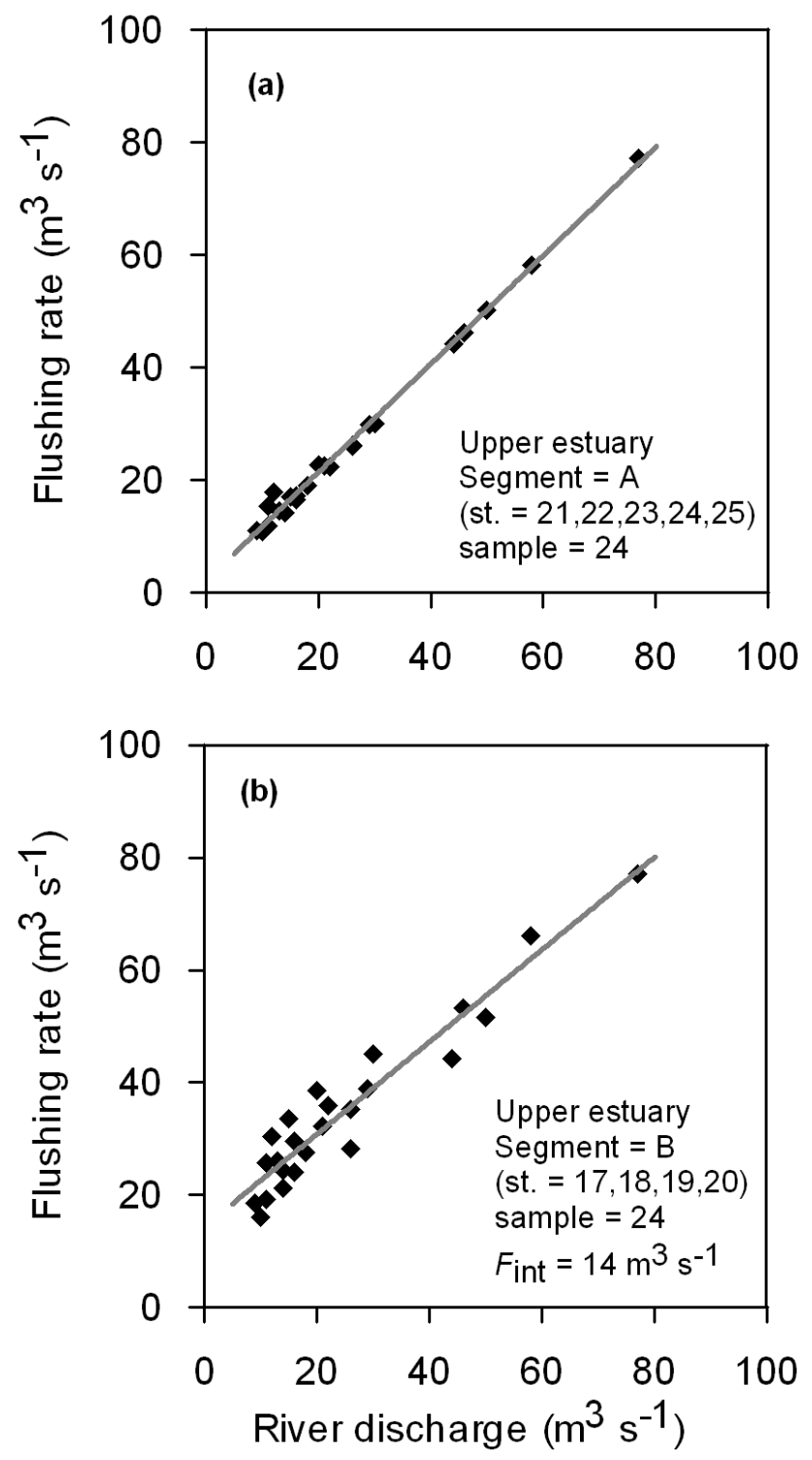

Fig. 10. Plot of flushing rate $(F)$ against river discharge $\left(Q_{f}\right)$ upstream of the Sumjin River estuary. The upper estuary, segment A, shows gravitational circulation flux, where the fitting line is linear with an intercept of zero and increasing $F$ value with increasing $Q_{f}$ value (a). The intercept value, $F_{\text {int }}$, in Segment B indicates the tidal flux, and the amount in excess of the intercept value indicates the gravitational circulation flux (b).

perform well under stratified conditions as well. The Sumjin River estuary has well- to partially-mixed characteristics during spring tide, but stratified conditions during neap tide. The Nguyen and Savenije (2006) model using Eqs. (6) and (7) yields better result during spring tide than during neap tide for predicting the salt intrusion length in the Sumjin River estuary (Table 3 ). The verification results show that the Nguyen and Savenije (2006) model is also applicable under stratified neap tide conditions. It should be noted that the use of the width convergence length rather than the area convergence length when calculating the dispersion coefficient at the mouth results in a more reasonable prediction of the salt intrusion length, whereas the determination of the width convergence length is simple and less data demanding.

\section{Summary}

Intensive field measurements have been carried out for three years to observe the salt intrusion at high and low waters during both spring and neap tide in the Sumjin River estuary. Based on the stratification parameter, the estuary had partially- to well-mixed characteristics during spring tide, but stratified conditions during neap tide. From our field observations, the salt intrusion at high water varied from $13.4 \mathrm{~km}$ in summer 2005 to $25.6 \mathrm{~km}$ in autumn 2006. The salt intrusion upstream mostly depends on river discharge rather than spring-neap tidal oscillation. Analyses of the three years of observed salinity data indicated that the scale of the salt intrusion length in the Sumjin River estuary is proportional to the river discharge to the $-1 / 5$ power.

Four empirical models have been applied to the Sumjin River estuary to predict the salt intrusion. Comparative results show that the Nguyen and Savenije (2006) model, developed under partially- and well-mixed estuaries, yields the most satisfactory result (least relative error of $4.6 \%$ ). As the model uses an exponential function of varying cross-section areas and contains more parameters than the other existing models, these are the probable reasons for its high capability to compute the salt intrusion length. Our study suggests that the model is also applicable under stratified neap tide conditions because it shows relative errors of 4.0 and $5.2 \%$ during spring and neap tide, respectively.

Acknowledgements. This research was supported by the Top Brand Project of Korea Ocean Research and Development Institute. The authors would like to acknowledge the members of the Earth Environment Prediction Laboratory for their enthusiastic supports during the data collection period. Two anonymous reviewers and editor are acknowledged for their constructive comments.

Edited by: H. H. G. Savenije

\section{References}

Aerts, J. C. J. H., Hassan, A., Savenije, H. H. G., and Khan, M. F.: Using GIS tools and rapid assessment techniques for determining salt intrusion: STREAM, a river basin management instrument, Phys. Chem. Earth, 25, 265-273, 2000.

Bowden, K. F.: The circulation, salinity and river discharge in the Mersey Estuary, Geophys. J. Roy Astr. S., 10, 383-400, 1966.

Davies, J. H.: A morphogenetic approach to world shorelines, Z. Geomorphol., 8, 127-142, 1964.

Dyer, K. R.: Estuaries, A Physical Introduction, John Wiley, London, UK, 2nd edn., 195 pp., 1997. 
Fischer, H. B., List, E. J., Koh, R. C. Y., Imberger, J., and Brooks, N. H.: Mixing in Inland and Coastal Waters, 1st edn., Academic Press, New York, USA, 483 pp., 1979.

Fischer, H. B.: Discussion of "Minimum length of salt intrusion in estuaries" by B. P. Rigter, 1973, J. Hydraul. Div. Proc., ASCE, 100, 708-712, 1974.

Geyer, W. R. and Signell, R. P.: A reassessment of the role of tidal dispersion in estuaries and bays, Estuaries, 15, 97-108, 1992.

Hansen, D. V. and Rattray Jr., M.: New dimensions in estuary classification, Limnol. Oceanogr., 11, 319-326, 1966.

Ji, Z. G.: Hydrodynamics and water quality: modeling rivers, lakes and estuaries, John Wiley, New Jersey, USA, 1st edn., 676 pp., 2008.

Kim, S. K., Kim, J. H., and Park, Y. J.: Water supply planning with inter-basin water transfer by an optimization model, Fourth international conference on Hydroscience and Engineering, International Association for Hydraulic Research, Korea, 2000, http:// syslab.korea.ac.kr/publication/File/ICHE2000_final_submit.pdf.

Lee, C. H.: Development of sustainable estuary management strategy in Korea II, Korea environment institute, Seoul, Korea, 2005.

Monismith, S. G., Kimmerer, W., Burau, J. R., and Stacey, M. T.: Structure and flow-induced variability of the subtidal salinity field in northern San Francisco Bay, J. Phys. Oceanogr., 32, 3003-3019, 2002.

Nguyen, A. D. and Savenije, H. H. G.: Salt intrusion in multichannel estuaries: a case study in the Mekong Delta, Vietnam, Hydrol. Earth Syst. Sci., 10, 743-754, 2006, http://www. hydrol-earth-syst-sci.net/10/743/2006/.

Oey, L. Y.: On steady salinity distribution and circulation in partially mixed and well mixed estuaries, J. Phys. Oceanogr., 14, 629-645, 1984.

Officer, C. B. and Kester, D. R.: On estimating the non-advective tidal exchanges and advective gravitational circulation exchanges in an estuary, Estuar. Coast. Shelf S., 32, 99-103, 1991.

Officer, C. B.: Physical Oceanography of Estuaries (and associated coastal waters), John Wiley, New York, USA, 465 pp., 1976.
Parsa, J., Etemad-Shahidi, A., Hosseiny, S., and YeganehBakhtiary, A.: Evaluation of computer and empirical models for prediction salinity intrusion in the Bahmanshir Estuary, J. Coast. Res., 50, 658-662, 2007.

Prandle, D.: On salinity regimes and the vertical structure of residual flows in narrow tidal estuaries, Estuar. Coast. Shelf S., 20, 615-635, 1985.

Pritchard, D. W.: The dynamic structure of a coastal plain estuary, J. Mar. Res., 15, 33-42, 1956.

Savenije, H. H. G.: Predictive model for salt intrusion in Estuaries, J. Hydrol., 148, 203-218, 1993.

Savenije, H. H. G.: Salinity and Tides in Alluvial Estuaries, 1st edn., Elsevier, Amsterdam, The Netherlands, 197 pp., 2005.

Savenije, H. H. G.: Comment on "A note on salt intrusion in funnelshaped estuaries: Application to the Incomati estuary, Mozambique" by Brockway et al. (2006), Estuar. Coast. Shelf S., 68, 703-706, 2006.

Sheldon, J. E. and Alber, M.: A comparison of residence time calculations using simple compartment models of the Altamaha River Estuary, Georgia, Estuaries, 25, 1304-1317, 2002.

Sheldon, J. E. and Alber, M.: The calculation of estuarine turnover times using freshwater fraction and tidal prism models: a critical evaluation. Estuar. Coast, 29, 133-146, 2006.

Thatcher, M. L. and Harleman, D. R. F.: A mathematical model for the prediction of unsteady salinity intrusion in estuaries. R. M. Parsons Laboratory for Water Resources and Hydrodynamics, Department of Civil Engineering, MI, Report No. 144, 232 pp., 1972.

Uncles, R. J. and Stephens, J. A.: Salt intrusion in the Tweed estuary, Estuar. Coast. Shelf S., 43, 271-293, 1996.

Van der Burgh, P.: Ontwikkeling van een methode voor het voorspellen van zoutverdelingen in estuaria, kanalen en zeeen, Rijkswaterstaat Rapport, 10-72, 1972 (in Dutch). 